\title{
10.5-eV Photoionization Mass Spectrometry of Aliphatic Compounds
}

\author{
S. E. Van Bramer* and M. V. Johnston* \\ Department of Chemistry and Biochemistry, Cooperative Institute for Research in Environmental Sciences, \\ University of Colorado, Boulder, Colorado, USA
}

\begin{abstract}
Vacuum ultraviolet photoionization by coherent $10.5-\mathrm{eV}$ radiation is evaluated for soft ionization of organic molecules. Coherent $10.5-\mathrm{eV}$ radiation is produced by frequency tripling the third harmonic of an Nd:YAG laser (355 nm) in a mixture of xenon and argon. $A$ number of intermediate size, $C_{6}$ to $C_{B}$, aliphatic compounds are studied to determine the extent and characteristics of fragmentation. Compared with 12-eV electron impact ionization, all show higher molecular ion abundances, less fragmentation, and significant enhancement of low energy rearrangement ions. n-Alkanes, alkenes, ketones, carboxylic acids, and ethers all form predominant molecular ions. Aldehydes and amines show significant molecular inn abundances but also extensive fragmentation. Branched alkanes, dienes, alcohols, and esters show little or no molecular ion, but do have a single dominant fragment ion. Metastable broadening in these spectra gives qualitative information on the energetics of low energy rearrangements. ( / Am Soc Mass Spectrom 1990, 1, 419-426)
\end{abstract}

S everal applications of coherent vacuum ultraviolet (VUV) photoionization have appeared over the past few years [1-6]. Although it is possible to generate coherent VUV radiation down to the LiF cutoff at $110 \mathrm{~nm}$ [7-12], $118 \mathrm{~nm}(10.5 \mathrm{eV})$ is perhaps the most convenient wavelength for mass spectrometry. It can be easily produced by frequency tripling the third harmonic of an Nd:YAG laser $(355 \mathrm{~nm})$ in a mixture of xenon and argon [13-15]. Because the photon energy is above yet close to the ionization potentials of most organic molecules, ionization should be fairly soft. Also, since no intermediate resonant states are required, single photon ionization is less selective than multiphoton ionization and therefore better suited to universal detection.

There are several experiments where soft, nonselective laser ionization is desirable. Coherent VUV radiation can be used to detect neutral products of unimolecular decomposition. For example, Welge and co-workers have identified neutral products from infrared multiphoton dissociation of 1,1,1-Trideuterio2,5-dithiahex-3-yne [1] and acetic anhydride [2] by postionization with $10.5-\mathrm{eV}$ radiation. Coherent VUV radiation can also be used to ionize desorbed neutrals. For example, Becker and co-workers have developed a method in which neutral molecules are desorbed from a surface by an $\mathrm{Ar}^{+}$beam [3-5] or a $\mathrm{CO}_{2}$ laser [6] and then ionized with $10.5-\mathrm{eV}$ radiation. In these

\footnotetext{
*Current address: University of Delaware, Department of Chemistry and Biochemistry, Newark, DE 19716.

Address reprint requests to $M, V$. Johnston, Department of Chemistry and Biochemistry. University of Delaware, Newark, DE 19716.
}

experiments, spectral interpretations are dependent upon the amount of fragmentation induced by the ionization step. Unfortunately, relatively little is known about the $10.5-\mathrm{eV}$ photoionization mass spectra of common organic compounds.

The advantages of low energy ionization can readily be seen when comparing low voltage electron impact (EI) with $70-\mathrm{eV}$ EI. Low voltage mass spectrometry has been used for several decades to simplify the mass spectra of complex mixtures of unsaturated compounds, as would be encountered with fossil fuel samples [16-19]. More recently, Maccoll and co-workers [20-31] have shown that 12-eV EI mass spectra of aliphatic compounds contain much higher molecular ion abundances and more structurally significant fragmentation than 70-eV EI. Arps et al. [32] have shown that $10.5-\mathrm{eV}$ coherent radiation can softly ionize small molecules and aromatic compounds. Larger aliphatic compounds, however, have not been studied. Continuous vacuum ultraviolet sources have been used to study wavelength dependent ionization and fragmentation of alkanes [33, 34] up to $C_{8}$, alkenes [33] up to $C_{6}$, dienes and alkynes [35] up to $C_{5}$, alcohols [36-38] up to $C_{3}$, ketones $[39,40]$ up to $C_{6}$, aldehydes [38] up to $C_{2}$, carboxylic acids [41] up to $C_{2}$, esters [41,38] up to $C_{6}$, and amines [38] up to $C_{3}$. The reported breakdown curves indicate that $10.5-\mathrm{eV}$ radiation should softly ionize many compounds.

In this article we report the $10.5-\mathrm{eV}$ photoionization mass spectra of aliphatic compounds in the $\mathrm{C}_{6}$ to $\mathrm{C}_{8}$ range. The compound classes studied include alkanes, alkenes, alcohols, aldehydes, ketones, carboxylic acids, esters, ethers, and amines. Two overall conclu- 


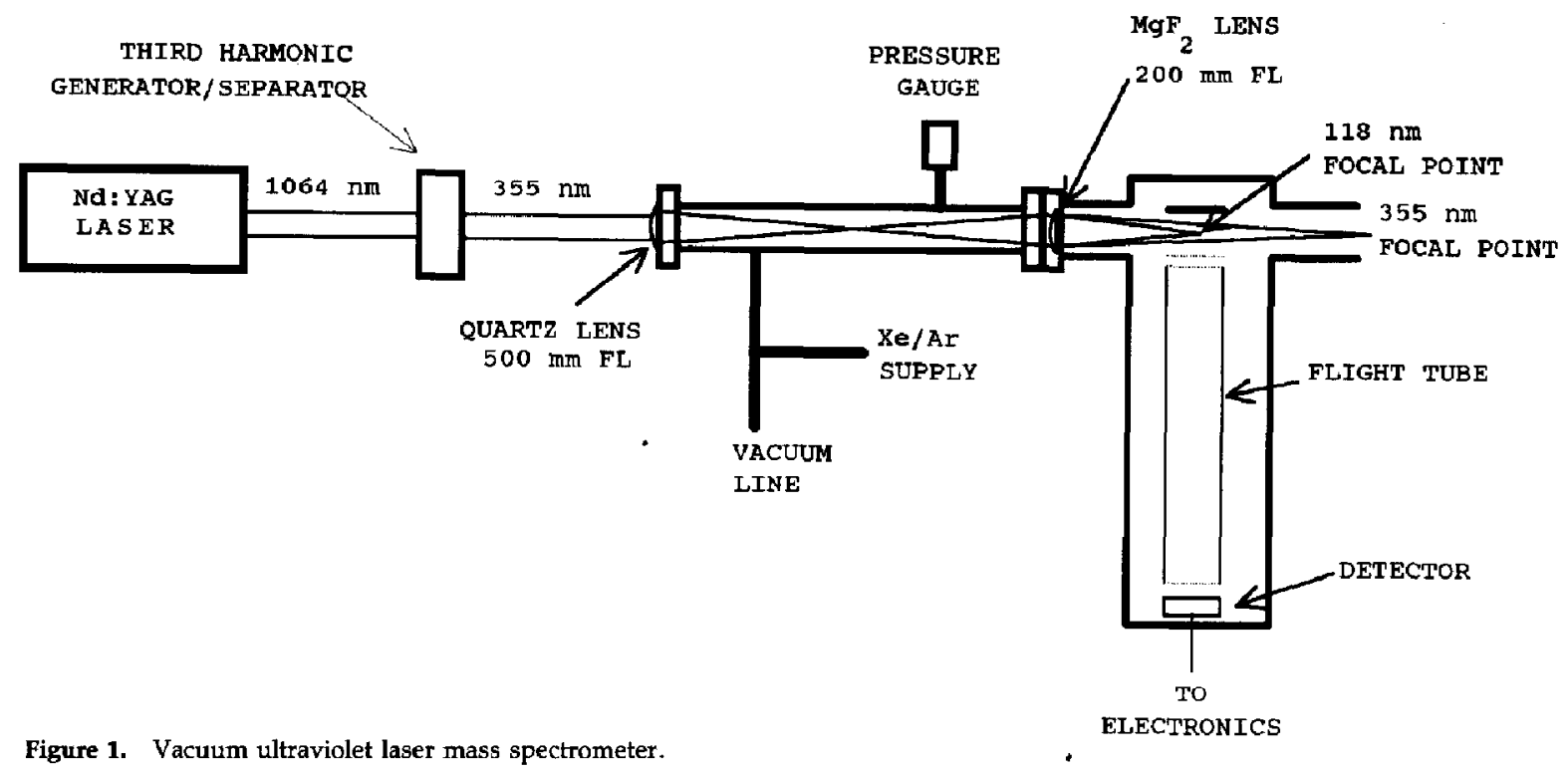

sions can be drawn from this work. First, $10.5-\mathrm{eV}$ photoionization gives higher molecular ion abundances and less fragmentation than 12-eV EI. Even so, many compounds exhibit surprisingly low molecular ion abundances with $10.5-\mathrm{eV}$ photoionization. In some cases, a single fragment ion dominates the mass spectrum, which can give a false impression that soft ionization has been achieved. Second, fragment ions resulting from low energy rearrangements are enhanced by $10.5-\mathrm{eV}$ photoionization even more so than by $12-\mathrm{eV}$ EL. Metastable broadening observed in the photoionization mass spectra has the added benefit of giving qualitative energetic information on these processes.

\section{Experimental}

By taking the third harmonic of a Spectra Physics (Mountain View, CA) DCR-2A Nd:YAG laser (355 $\mathrm{nm})$ and focusing it in the center of an $\mathrm{Xe} / \mathrm{Ar}$ cell with a $500 \mathrm{~mm}$ f.l. quartz lens, $118 \mathrm{~nm}$ coherent radiation is produced. A diagram of the $\mathrm{Xe} / \mathrm{Ar}$ cell and the mass spectrometer is shown in Figure 1. The cell is a stainless steel tube $3.7 \mathrm{~cm}$ in diameter and $1 \mathrm{~m}$ long with conflat flanges welded on each end. At one end, a quartz window is epoxyed (torr seal, Varian, Lexington, MA) into the mating flange. At the other end, a $\mathrm{MgF}_{2}$ lens (200 mm f.l., Oriel, Stratford, CT) is epoxyed into the mating flange, which is then bolted to the mass spectrometer. To ensure small leak rates, a bellows valve (Nupro, Willoughby, $\mathrm{OH}$ ) is used to connect the cell to the gas filling and pump out lines, and Ultra-torr (Cajon, Macedonia, $\mathrm{OH}$ ) fittings are used wherever possible. The mass spectrometer is a custom-built time-of-flight instrument. The width of the source region is $11 \mathrm{~mm}$; the secondary acceleration region, $4 \mathrm{~mm}$; the flight tube, $968 \mathrm{~mm}$; and the postacceleration region, $15 \mathrm{~mm}$. Voltages used are as follows: backing plate, $+3000 \mathrm{~V}$; first grid, $+2600 \mathrm{~V}$; flight tube, ground; and detector, $-2500 \mathrm{~V}$. Ions are detected by a dual microchannel plate detector (R. $\mathbf{M}$. Jordan Co., Grass Valley, CA). The transient ion current is sampled by a Nicolet (Madison, WI) model 4094 digital oscilloscope with a model $4180200 \mathrm{Mhz}$ plug-in and transferred to a PC for normalization and plotting.

The laser beam is directed into the source region. Because of the large difference in the refractive index for $\mathrm{MgF}_{2}$ at $355 \mathrm{~nm}$ (1.401) and $118 \mathrm{~nm}$ (1.679) [42], the 118-nm beam is focused in the center of the source region, $147 \mathrm{~mm}$ from the lens, whilc the $355-\mathrm{nm}$ beam is focused $162 \mathrm{~mm}$ beyond the 118-nm focal point.

The Xe/Arcell was first evacuated to less than $10^{-5}$ torr by a 2" diffusion pump with a dry ice/acetone cold trap. Then it was heated to $80^{\circ} \mathrm{C}$ under vacuum for several days. Next, 16 torr xenon (Matheson, East Rutherford, $\mathrm{NJ}, 99.999 \%$, research purity) and 160 torr argon (Matheson, 99.9995\%, research purity) were added to the cell, and mixed for five to ten minutes by sliding a magnetic stir bar back and forth inside. This mixture was then used for several days before VUV efficiency dropped off. Rare gas pressures were measured with an Omega (Stamford, CT) model PX 621 pressure transducer $( \pm 1$ torr accuracy). This was important because the pressure range over which the $\mathrm{Xe} / \mathrm{Ar}$ mixture is correctly phase matched is fairly narrow [13].

Naphthalene, toluene, and ethanol, which show only a molecular ion at $10.5 \mathrm{eV}$, were used to calibrate the mass spectrometer. All compounds, except heptanoic acid and octanoic acid, were introduced by a room temperature molecular leak. Heptanoic acid and octanoic acid were introduced by a heated molecular leak. The source region was at room temperature, and 
the source pressure was less than $3 \times 10^{-6}$ torr. One thousand shots were averaged for each spectrum. For the spectra shown in this article the 355-nm pulse energy into the $\mathrm{Xe} / \mathrm{Ar}$ cell was maintained at ca. 8-10 $\mathrm{mJ} /$ pulse. The threshold for VUV photoionization of naphthalene was $3.4 \mathrm{~mJ} / \mathrm{pulse}$. Because the $355-\mathrm{nm}$ beam was not focused at the same point as the 118-nm beam and because the beam is doughnut shaped, the 355-nm flux at the focal point of the 118-nm beam was rather low and few multiphoton effects were seen at low power. Spectra taken with higher pulse energies, up to $30 \mathrm{~mJ} /$ pulse, exhibited significant multiphoton effects.

3-Octanol (98\%), octanal, 2-octanone (95\%), 4heptanone (98\%), 3-octanone $(99 \%)$, pentanal $(99+$ $\%)$, hexanal $(99 \%)$, heptanal $(95 \%)$, 1-octene $(97 \%)$, 2-octene (98\%), 4-octene (99\%), 1,7-octadiene (98.5\%), propyl propionante $(99 \%)$, butyl butyrate $(98 \%)$, dipropyl ether $(99+\%)$, dibutyl ether $(99+\%)$, heptylamine $(99 \%)$, octylamine (99\%), 2,2-dimethylhexane (99\%), and heptanoic acid (99\%) were obtained from Aldrich (Milwaukee, WI); 1-octanol, 2-octanol, octanoic acid and $n$-octane from Eastman Kodak (Rochester, NY); toluene and naphthalene from Fischer (Waukesha, WI); 1-pentanol from Mallinkrodt (St. Louis, MO); butanal from Matheson, Coleman and Bell; and ethanol from Midwest Grain. All compounds were used without further purification.

\section{Results}

Alkanes. The 10.5-eV photoionization mass spectrum of $n$-octane is shown in Figure 2a. The molecular ion $(m / z 114)$ is the base peak. The two fragment ions at $m / z 43$ and $m / z 57$ are due to subsequent absorption of a 355-nm photon [33] (see Discussion). In contrast, the 12-eV EI mass spectrum contains a series of $\mathrm{C}_{n} \mathrm{H}_{2 n+1}^{+}$and $\mathrm{C}_{n} \mathrm{H}_{2 n}^{+\cdot}$ ions. The base peak is $m / z 85$, and the molecular ion abundance is $97 \%$ [25]. The 10.5-eV photoionization spectrum of 2,2-dimethylhexane, Figure $2 b$, shows the effect of branching. The base peak, $\mathrm{C}_{4} \mathrm{H}_{8}^{+\cdot}(m / z 56)$, is characteristic of di-substitution at the 2 position [25]. The molecular ion $(\mathrm{m} / \mathrm{z}$ 114; $7 \%)$ and an $\alpha$-cleavage ion $\left[\mathrm{M}-\mathrm{CH}_{3}\right]^{+}(m / z$ 99) are also observed. In the $70-\mathrm{eV}$ EI spectrum, the molecular ion abundance is less than $0.1 \%$ of the base peak at $m / z 55$.

Alkenes. 1-Octene, 2-octene, and 4-octene all have similar 10.5-eV photoionization mass spectra. The spectrum of 1-octene is shown in Figure 2c. The molecular ion at $m / z 112$ is the base peak. Two series of ions are observed that correspond to $\left[\mathrm{M}-\mathrm{C}_{\mathrm{n}} \mathrm{H}_{2 \mathrm{n}+1}\right]^{+}$ $\left(m / z 41,55,69\right.$, and 83) and $\left[\mathrm{M}-\mathrm{C}_{\mathrm{n}} \mathrm{H}_{2 \mathrm{n}}\right]^{+-}(m / z 42,56$, 70 , and 84$)$. Several peaks $(m / z 70,83$, and 84$)$ are metastably broadened. The $12-\mathrm{eV}$ EI spectra of 1-octene, 2-octene, and 4-octene also have the molecular ion for the base peak; however, the two fragmentation series are greatly enhanced [27]. The spectrum of 1,7-octadiene, Figure $2 \mathrm{~d}$, shows the effect of multiple

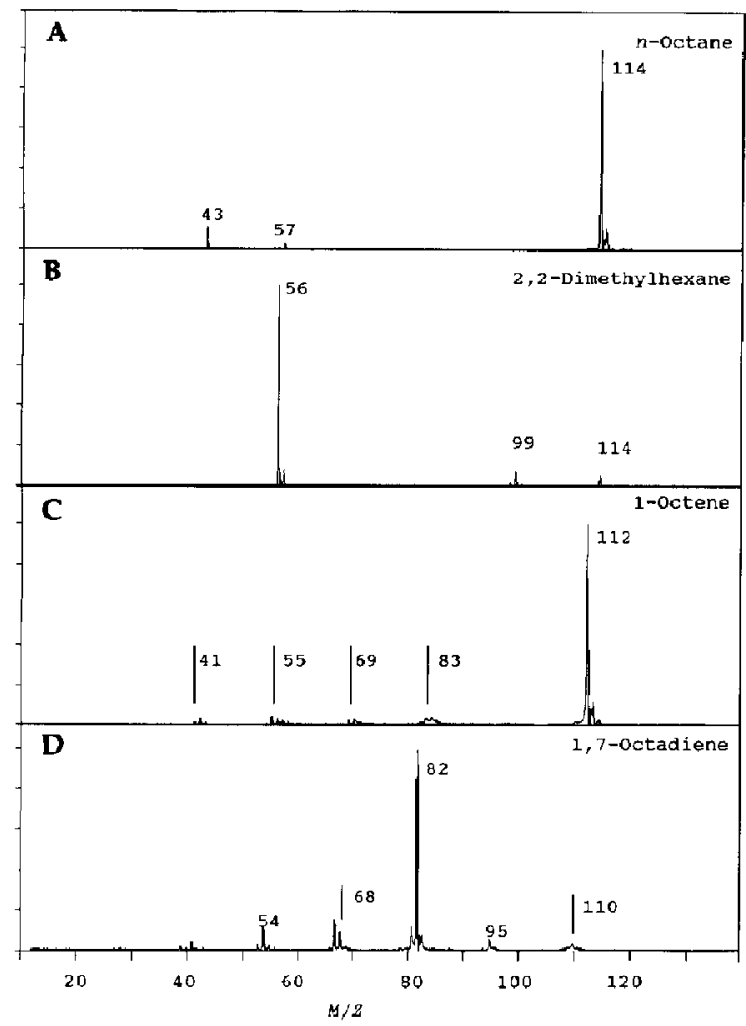

Figure 2. 10.5-eV photoionization mass spectra of (a) n-octane, (b) 2,2-dimethylhexane, (c) 1-octene, and (d) 1,7-octadiene.

double bonds. The molecular ion ( $m / z 110)$ relative abundance is only $6 \%$ of the base peak at $m / z 82$. Two series of ions are observed that correspond to $\left[\mathrm{M}-\mathrm{C}_{\mathrm{n}} \mathrm{H}_{2 \mathrm{n}}\right]^{+\cdot}(m / z 54,68,82)$ and $\left[\mathrm{M}-\mathrm{C}_{\mathrm{n}} \mathrm{H}_{2 \mathrm{n}+1}\right]^{+}(m / z$ 53, 67, 81, and 95). In the 70-eV EI spectrum, the molecular ion abundance is only $0.5 \%$ of the base peak at $m / z 41$.

Alcohols. The $10.5 \mathrm{eV}$ photoionization spectra of 1pentanol and 1-octanol, 2-octanol, and 3-octanol are shown in Figure 3a-d, respectively. Only 1-octanol gives a molecular ion $(m / z 130)$, while $\left[\mathrm{M}-\mathrm{H}_{2}\right]^{+{ }^{+}}$is seen for 1-pentanol ( $\mathrm{m} / \mathrm{z} 86), 2$-octanol, and 3-octanol $(m / z$ 128). All four compounds have a predominant ion that corresponds to $\left[\mathrm{M}-\mathrm{H}_{2} \mathrm{O}\right]^{+}, m / z$ 70 for pentanol and $m / z 112$ for the octanols. Subsequent decomposition of $\left[\mathrm{M}-\mathrm{H}_{2} \mathrm{O}\right]^{+}$is similar to that discussed previously for the alkenes. Alkene-type fragmentation is observed for 1-pentanol, 1-octanol, and 2-octanol. All show a series of $\mathrm{C}_{n} \mathrm{H}_{2 n-1}^{+}$and $\mathrm{C}_{n} \mathrm{H}_{2 n}^{+\cdot}$ ions. As in the alkene spectra, the relative abundances of these ions are very low. 2-Octanol shows a weak $\alpha$-cleavage ion $(m / z 115)$. 3-Octanol shows two $\alpha$-cleavage ions corresponding to $\left[\mathrm{M}-\mathrm{C}_{2} \mathrm{H}_{5}\right]^{+}(m / z 101)$ and $[\mathrm{M}$ $\left.\mathrm{C}_{5} \mathrm{H}_{11}\right]^{+}(m / z 59)$. Several higher mass ions are present in 1-pentanol, which suggest the presence of a dimer or a contaminant. In the former case, $m / z 158$ corresponds to $\left[2 \mathrm{M}-\mathrm{H}_{2} \mathrm{O}\right]^{\star *}$. 


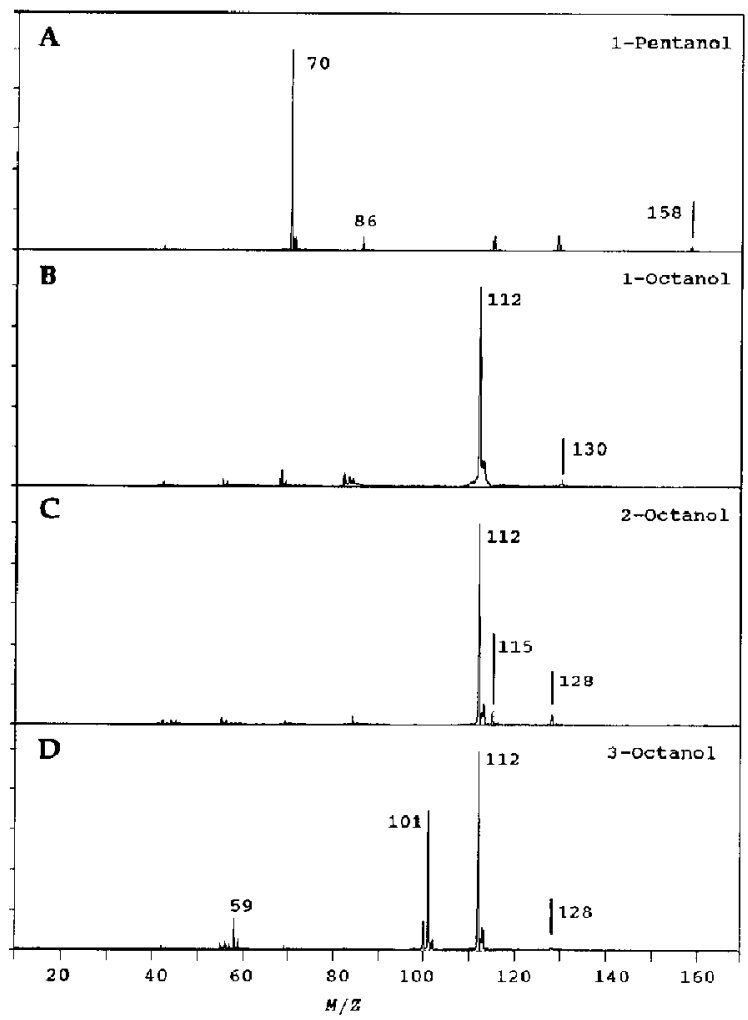

Figure 3. 10.5-eV photoionization mass spectra of (a) pentanol, (b) 1-octanol, (c) 2-octanol, and (d) 3-octanol.

The absence of molecular ions for most of these compounds is not surprising because they are rarely observed in 12-eV EI mass spectra [25]. $\left[\mathrm{M}-\mathrm{H}_{2} \mathrm{O}\right]^{+\cdot}$ is more abundant and other fragment ions are signifcantly weaker with $10.5-\mathrm{eV}$ photoionization than with 12-eV EI. A molecular ion is observed for 1-octanol with $10.5-\mathrm{eV}$ photoionization but not with 12-eV EI.

Aldehydes. The 10.5-eV photoionization mass spectra of butanal, pentanal, hexanal, heptanal, and octanal are shown in Figure 4. Because of the large number of low energy rearrangements possible, these spectra are dominated by odd electron, even mass, ions. The spectrum of butanal, Figure $4 \mathrm{a}$, contains only the molecular ion $(m / z, 72)$. The spectrum of pentanal is shown in Figure $4 \mathrm{~b}$. The molecular ion $(\mathrm{m} / \mathrm{z} 86)$ relative abundance is $52 \%$ of the base peak, $\left[\mathrm{M}-\mathrm{C}_{2} \mathrm{H}_{4}\right]^{+\cdot}$ $(m / z$ 58). McLafferty and McLafferty +1 rearrangement ions are abserved ( $m / z 44$ and 45 ). The spectrum of hexanal, Figure $4 c_{r}$ contains a molecular ion $(\mathrm{m} / \mathrm{z}$ $100 ; 57 \%),\left[\mathrm{M}^{-} \mathrm{H}_{2} \mathrm{O}\right]^{+\cdot}(\mathrm{m} / \mathrm{z}$ 82; base peak), two [M$\left.\mathrm{C}_{\mathrm{n}} \mathrm{H}_{2 n}\right]^{+\cdot}$ ions $(m / z 58$ and 72$)$, and the McLafferty complement $(m / z 56)$. McLafferty and McLafferty +1 ions are observed $(m / z 44$ and 45$)$, but they are very weak. The mass spectrum for heptanal, Figure $4 \mathrm{~d}$, is very similar to hexanal. The molecular ion $(m / z 114)$ is the base peak. Other predominant ions are $\left[\mathrm{M}-\mathrm{H}_{2} \mathrm{O}\right]^{+}$

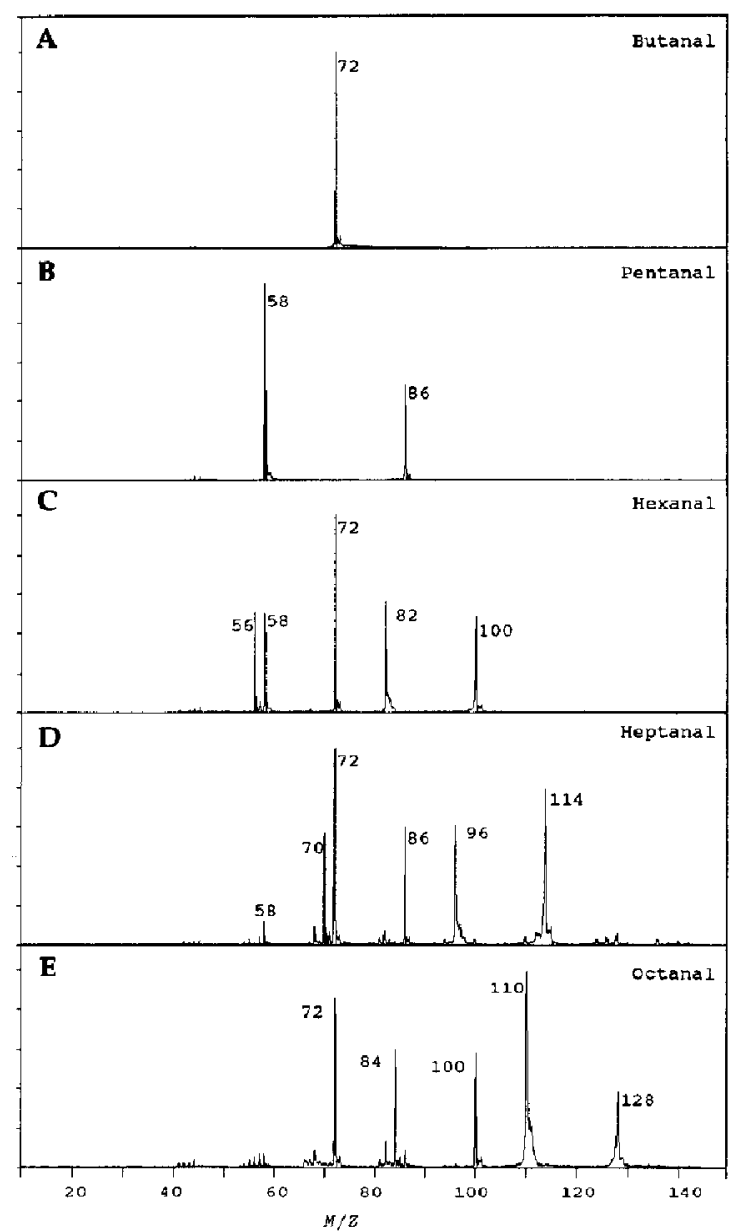

Figure 4. $10.5-\mathrm{eV}$ photoionization mass spectra of (a) butanal, (b) pentanal, (c) hexanal, (d) heptanal, and (e) octanal.

( $m / z 96)$, three $\left[\mathrm{M}-\mathrm{C}_{\mathrm{n}} \mathrm{H}_{2 \mathrm{n}}\right]^{+-}$ions $(m / z 58,72$, and 86$)$, the McLafferty complement $(m / z \quad 70)$, and weak McLafferty and McLafferty +1 ions $(m / z 44$ and 45$)$. The spectrum of actanal, Figure $4 \mathrm{e}$, is very similar to heptanal and hexanal. It shows a molecular ion $(\mathrm{m} / \mathrm{z}$ 128; 36\%), $\left[\mathrm{M}-\mathrm{H}_{2} \mathrm{O}\right]^{+\cdot}(m / z 110)$, two $\left[\mathrm{M}-\mathrm{C}_{\mathrm{n}} \mathrm{H}_{2 \mathrm{n}}\right]^{+}$ ions $(m / z 100,72)$, a McLafferty complement $(m / z 84)$, and weak McLafferty and McLafferty +1 ions $(m / z 44$ and 45). The $\left[\mathrm{M}-\mathrm{H}_{2} \mathrm{O}\right]^{+}$peak is metastably broadened in the spectra of hexanal, heptanal, and octanal. Relative to 12-eV EI $[24,25]$ all of the major odd electron ions are enhanced in the $10.5-\mathrm{eV}$ photoionization mass spectrum. The molecular ion relative abundance is also enhanced, typically by a factor of 5 .

Ketones. The $10.5-\mathrm{eV}$ photoionization spectra of 2-octanone, 3-octanone, and 4-heptanone are shown in Figure 5. All three compounds exhibit predominant molecular ions with relatively little fragmentation. The 


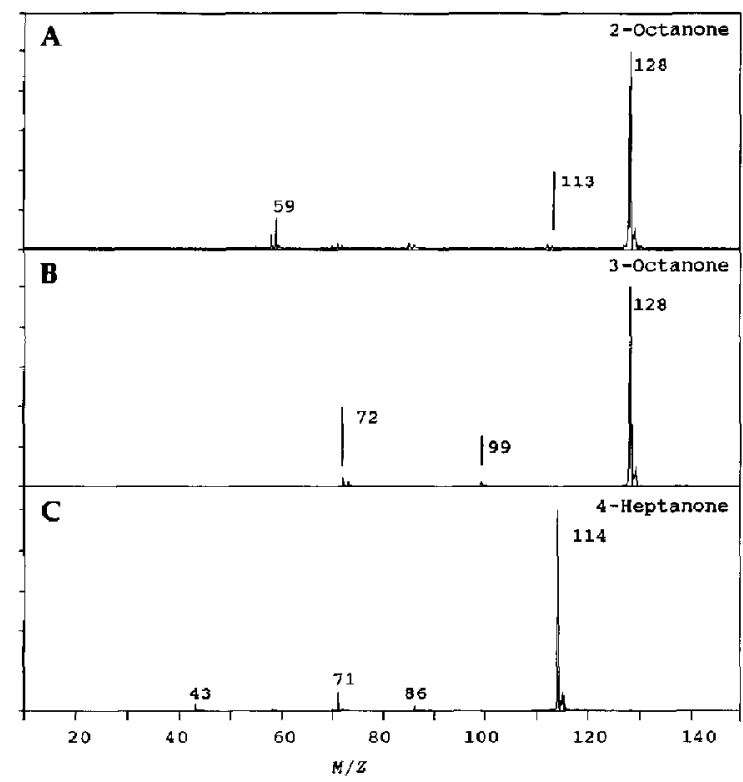

Figure 5. 10.5-eV photoionization mass spectra of (a) 2-octanone, (b) 3-octanone, and (c) 4-heptanone.

spectrum of 2-octanone, Figure 5a, shows a McLafferty ion $(m / z 58)$, a McLafferty +1 ion $(m / z 59)$, and a metastable $\alpha$-cleavage ion $(m / z 113)$. The spectrum of 3-octanone, Figure $5 \mathrm{~b}$, is very similar to 2-octanone, with a McLafferty ion $(m / z 72)$, a McLafferty +1 ion $(m / z 73)$, and a metastable $\alpha$-cleavage ion $(m / z 99)$. The spectrum of 4-heptanone, Figure $5 \mathrm{c}$, shows a significantly stronger $\alpha$-cleavage ion $(m / z 71)$, a McLafferty ion $(m / z 86)$, and a McLafferty complement $(m / z 43)$. The 12-eV EI spectrum of 2-octanone [25] has much more abundant fragment ions, but the molecular ion is still the base peak.

Carboxylic acids. The $10.5-\mathrm{eV}$ photoionization mass spectrum of $n$-heptanoic acid, Figure $6 a$, shows a predominant molecular ion $(m / z 130)$. Other ions include the McLafferty ion ( $m / z$ 60; metastably broadened), the McLafferty +1 ion $(m / z$ 61; metastably broadened), the McLafferty complement $(\mathrm{m} / \mathrm{z} \quad 70$; metastably broadened), and $\left[\mathrm{M}-\mathrm{C}_{2} \mathrm{H}_{4}\right]^{+\cdot}$ ( $m / z$ 102). The 12-eV EI spectrum of heptanoic acid [30] is much more congested; the McLafferty ion ( $m / z 60)$ is the base peak, and the molecular ion abundance is only $6 \%$. The $10.5-\mathrm{eV}$ photoionization mass spectrum of $n$-octanoic acid, Figure $6 \mathrm{~b}$, also exhibits a predominant molecular ion $(m / z 144)$ and a McLafferty complement $(m / z 84)$, which is metastably broadened. The McLafferty ion $(\mathrm{m} / \mathrm{z} 60)$ and a cleavage ion $(\mathrm{m} / \mathrm{z}$ 73) corresponding to $\left[\mathrm{M}-\mathrm{C}_{5} \mathrm{H}_{11}\right]^{+}$are also present. The 12-eV EI spectrum of octanoic acid [30], like that of heptanoic acid, is much more congested; the McLafferty ion $(m / z 60)$ is the base peak, and the molecular ion relative abundance is only $16 \%$.

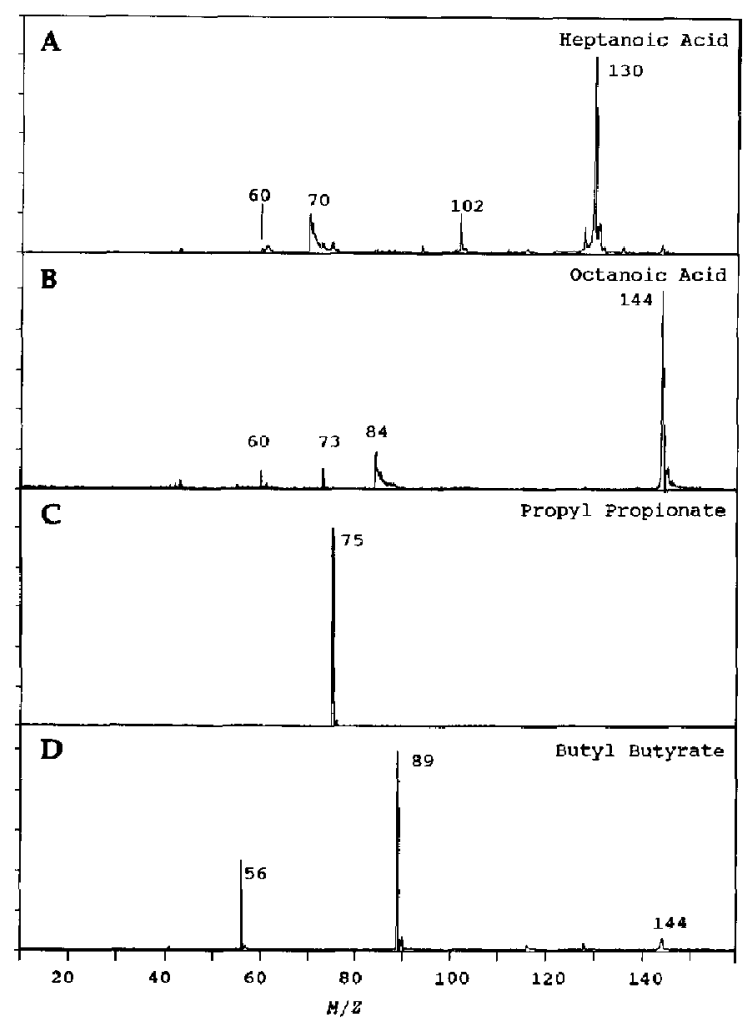

Figure 6. 10.5-eV photoionization mass spectra of (a) heptanoic acid, (b) octanoic acid, (c) propyl propionate, and (d) butyl butyrate.

Esters. The 10.5-eV photoionization mass spectrum of propyl propionate is shown in Figure 6c. The molecular ion is present but its abundance is only $0.4 \%$. The only substantial peak is a highly resonance stabilized McLafferty +1 ion $\left[\mathrm{M}-\mathrm{C}_{3} \mathrm{H}_{5}\right]^{+}(m / z 75)$. The 70-eV EI spectrum has a molecular ion abundance of less than $1 \%$, but it is very congested with six major peaks of greater than $20 \%$ relative abundance. The $10.5-\mathrm{eV}$ photoionization spectrum of butyl butyrate, Figure $6 \mathrm{~d}$, also has a strong McLafferty +1 peak $(m / z 89)$. The molecular ion $(m / z 144 ; 12 \%)$, and the McLafferty complement from the butyl end, $\left[\mathrm{C}_{4} \mathrm{H}_{8}\right]^{+\cdot}(m / z 56)$, are also present. The $12-\mathrm{eV}$ EI mass spectrum is very similar [25], but there are additional peaks at $\mathrm{m} / \mathrm{z} 70$ and 101 . The $70-\mathrm{eV}$ spectrum is very congested, and has a molecular ion abundance of less than $0.01 \%$.

Ethers. The $10.5-\mathrm{eV}$ photoionization mass spectrum of propyl ether, Figure $7 \mathrm{a}$, shows a predominant molecular ion $(m / z 102), \alpha$-cleavage to form $\mathrm{C}_{3} \mathrm{H}_{7}^{+}$ $(m / z 43)$, and $\beta$-cleavage to give $\left[\mathrm{M}-\mathrm{C}_{2} \mathrm{H}_{5}\right]^{+}(m / z 73)$. The 70-eV EI spectrum of propyl ether has a molecular ion abundance of $11 \%$, and $m / z 43$ is the base peak. The $10.5-\mathrm{eV}$ photoionization spectrum of butyl 


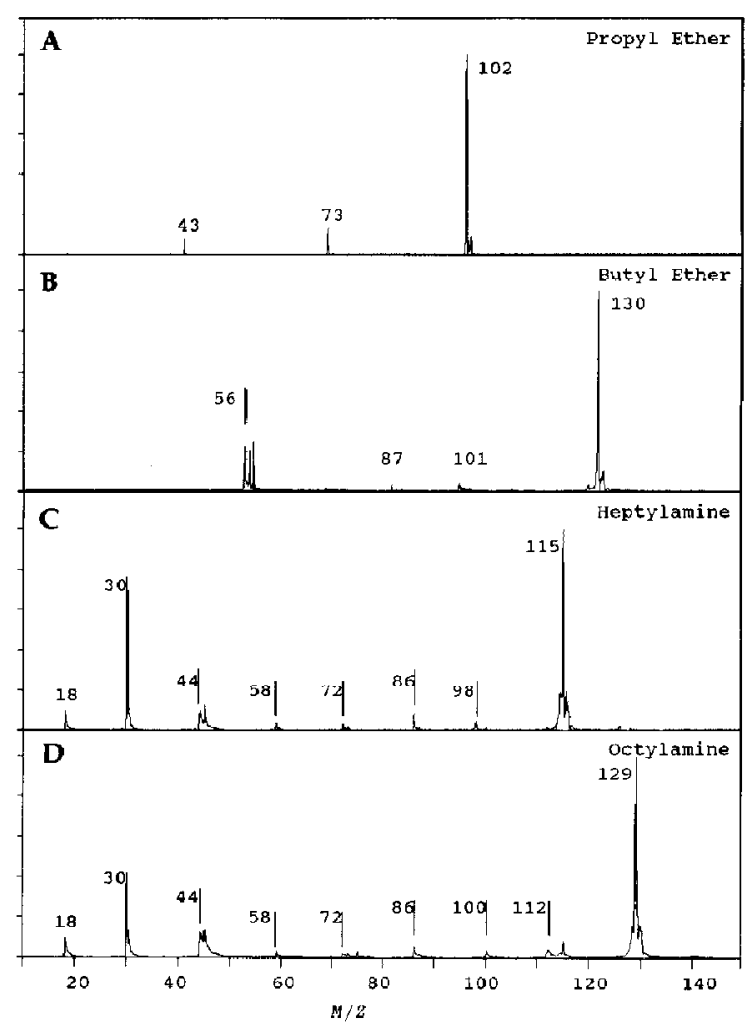

Figure 7. $10.5-\mathrm{eV}$ photoionization mass spectra of (a) propyl ether, (b) butyl ether, (c) heptylamine, and (d) octylamine.

ether, Figure $7 \mathrm{~b}$, also shows a predominant molecular ion. The largest fragment ions are $\alpha$-cleavage to give $\mathrm{C}_{4} \mathrm{H}_{9}^{+}(m / z 57), \mathrm{C}_{4} \mathrm{H}_{8}^{+-}(m / z 56)$, which is metastably broadened, and $\mathrm{C}_{4} \mathrm{H}_{10}^{+}(m / z 58)$. Weak $\beta$-cleavage to form $\left[\mathrm{M}-\mathrm{C}_{3} \mathrm{H}_{7}\right]^{+}(\mathrm{m} / \mathrm{z} 87)$, and metastable $\gamma$-cleavage to form $\left[\mathrm{M}-\mathrm{C}_{2} \mathrm{H}_{5}\right]^{+}(\mathrm{m} / \mathrm{z}$ 101) are also observed; 70-eV EI gives predominantly $\alpha$-cleavage with a molecular ion abundance of only $2 \%$.

Amines. The $10.5-\mathrm{eV}$ photoionization mass spectrum of $n$-heptylamine is shown in Figure 7c. The molecular ion $(m / z 115)$ is the base peak. Other ions observed include $\mathrm{NH}_{4}^{+}(m / z 18),\left[\mathrm{M}-\mathrm{NH}_{3}\right]^{+^{-}}(m / z 98)$, which is uncommon for amines, and a series of $[\mathrm{M}$ $\left.\mathrm{C}_{n} \mathrm{H}_{2 \mathrm{n}+1}\right]^{+}$cleavage ions ( $m / z 30,44,58,72$, and 86 ). Virtually all of the fragment ions are metastably broadened. The 12-eV EI spectrum shows similar cleavage ions. However, the molecular ion abundance is only $21 \%$ of the base peak at $m / z 30$ [23]. The $10.5-\mathrm{eV}$ photoionization spectrum of $n$-octylamine, Figure $7 \mathrm{~d}$, is similar. The molecular ion $(m / z 129)$ is the base peak. $\mathrm{NH}_{4}^{+}(m / z 18),\left[\mathrm{M}-\mathrm{NH}_{3}\right]^{+-}(m / z 112)$, and a series of $\left[\mathrm{M}-\mathrm{C}_{\mathrm{n}} \mathrm{H}_{2 \mathrm{n}+1}\right]^{+}$cleavage ions $(m / z 30$, 44, 58, 72, 86, and 100) are all seen. Like heptylamine, all of the fragment ions are metastably broadened. The 12-eV EI mass spectrum [23] of octylamine is dominated by the series of cleavage ions, but the molecular ion abundance is only $15 \%$ of the base peak at $m / z 44$ [23].

\section{Discussion}

The $10.5-\mathrm{eV}$ photoionization mass spectra of aliphatic compounds in the $C_{6}$ to $C_{8}$ range exhibit higher molecular ion abundances and less fragmentation than with 12- or 70-eV El. Even so, soft ionization is not uniformly achieved. Of the compounds studied here and in the literature [33-41], n-alkanes, alkenes, ketones, carboxylic acids, and ethers all form predominant molecular ions. Aldehydes and amines show significant molecular ion abundances but also extensive fragmentation. Branched alkanes, dienes, alcohols, and esters show little or no molecular ion but do have a single dominant fragment ion. For these compounds, the 10.5-eV spectra might be considered less informative than their $12-\mathrm{eV}$ counterparts because the abundances of other fragment ions necessary to establish the molecular structure and hence molecular mass are so small. For example, it is impossible to deduce the molecular structure of propyl propionate from the 10.5-eV mass spectrum (Figure 6a). The 70-eV EI spectrum, however, contains many additional ions such as $m / x 31,43,57$, and 87 , which provide significant structural information. Because such fragmentation can occur, experiments using $10.5 \mathrm{eV}$ coherent radiation for soft ionization must be carefully designed with respect to the compounds involved.

Low voltage mass spectrometry can greatly simplify the mass spectra of complex mixtures. This allows the physical properties of a mixture to be determined from the structural information present in the corresponding mass spectrum [16-19]. The relatively facile fragmentation of aliphatic compounds, however, has restricted this method to mixtures of olefinic and aromatic compounds [16]. Our results suggest that photoionization mass spectrometry would be capable of analyzing mixtures of aliphatic compounds. The small amount of fragmentation caused by $10.5-\mathrm{eV}$ photoionization could be even further reduced by generating tunable coherent vacuum ultraviolet radiation in the 9- to $10-\mathrm{eV}$ region.

The total ion current for naphthalene with $10.5-\mathrm{eV}$ photoionization is comparable to what we normally obtain with multiphoton ionization at $266 \mathrm{~nm}$. This observation suggests that absolute detection limits for photoionization by coherent vacuum ultraviolet radiation, as with multiphoton ionization [43], will be in the low picogram range. Unlike multiphoton ionization, relative ion abundances in photoionization mass spectra are independent of the laser pulse energy, assuming that the effects of the remaining ultraviolet pump radiation can be eliminated. Absolute ion abundances, however, are pulse energy dependent for both single photon and multiphoton ionization.

Metastably broadened fragment ions are observed 
in most of the photoionization mass spectra. Because a significant fraction of the overall fragmentation occurs on a slow time-scale, the mass spectra observed will be highly sensitive to the particular ion extraction conditions and mass analyzer used. Therefore, the relative ion abundances given in the Results section should be taken with caution. Several aldehyde and carboxylic acid spectra are particularly interesting because they contain only one metastably broadened primary fragment ion. This observation suggests that the metastable ion is the lowest appearance energy fragment ion. In the photoionization mass spectra of hexanal, heptanal, and octanal (Figure 4), $\left[\mathrm{M}-\mathrm{H}_{2} \mathrm{O}\right]^{+\cdot}$ is the only metastable ion observed. Assigmment of this ion as the lowest appearance energy ion is consistent with thermodynamic calculations of the enthalpies of reaction. $\Delta \mathrm{H}^{\circ}$ for $\left[\mathrm{M}-\mathrm{H}_{2} \mathrm{O}\right]^{+-}$formation is thought to be only a few tenths of an eV over the ionization energy for pentanal and hexanal [24]. In contrast, $\Delta \mathrm{H}^{\circ}$ for formation of the McLafferty ion and its complement are at least an $\mathrm{eV}$ above the ionization energy for pentanal through octanal [27]. Our spectra are consistent with these data and with the observation that metastable transitions, as revealed by $\mathrm{B} / \mathrm{E}$ scans, show that $\left[\mathrm{M}-\mathrm{H}_{2} \mathrm{O}\right]^{+-}$is by far the most abundant ion [24]. In the photoionization mass spectrum of octanoic acid (Figure 6b), the McLafferty complement $(m / z 84)$ is metastably broadened whereas the McLafferty ion $(m / z 60)$ is not. This observation is consistent with thermodynamic calculations that show a smaller $\Delta \mathrm{H}^{\circ}$ for formation of the McLafferty complement than for the McLafferty ion [27]. The photoionization mass spectrum of heptanoic acid (Figure 6a) is less informative because both the McLafferty complement $(m / z 70)$ and McLafferty ion $(m / z 60)$ are metastably broadened. One possibility for future work is to use tunable vacuum ultraviolet radiation to determine fragment ion appearance energies. This information could help distinguish among the possible reaction products. For example, $\Delta \mathrm{H}^{\circ}$ for formation of the McLafferty complement in heptanoic acid and octanoic acid changes by ca. $0.6 \mathrm{eV}$ depending upon whether a 1-alkene or a 2-alkene is produced [27].

Because of the large amount of $355-\mathrm{nm}$ radiation present, difficulties were anticipated from multiphoton effects. Although $355 \mathrm{~nm}$ was not eliminated, several steps were taken to ensure that its effect was minimal. The focal parameters of the lens system caused the $355-\mathrm{nm}$ radiation to be focused at a different location from $118 \mathrm{~nm}$. At the 118-nm focal point, the $355-\mathrm{nm}$ beam was still $5 \mathrm{~mm}$ in diameter. In addition, the doughnut shaped beam profile of the Nd:YAG laser caused the 355-nm flux to be much lower at the focal point of the 118-nm beam than on the periphery. A number of the compounds were run at pump laser powers from 10 to $30 \mathrm{~mJ} /$ pulse to determine the effect of 355-nm radiation. These spectra showed an increase in the relative abundance of small, even electron fragment ions. Naphthalene. which will not fragment with less than two additional 355-nm photons after absorbing a 118-nm photon [44], did not show any fragmentation at pump laser powers less than $30 \mathrm{~mJ} /$ pulse. The $10.5-\mathrm{eV}$ photoionization spectrum of $n$-octane gives two fragments, $m / z 43$ and 57 . From the breakdown curve for $n$-octane at $300 \mathrm{~K}$ [33], $m / z 43$ and 57 have appearance energies of 11.14and 11.11-eV, respectively. These ions must arise from multiphoton effects. The low, less than $10 \%$, relative abundances of $m / z 43$ and 57 indicate, however, that multiphoton effects for $n$-octane are relatively small. All of the photoionization mass spectra obtained at the lowest 355-nm pulse energy show higher molecular ion abundances and less fragmentation than their 12-eV EI counterparts. Because the energy of one $118-\mathrm{nm}$ photon plus one $355-\mathrm{nm}$ photon is $14.0 \mathrm{eV}$, this observation suggests that the major features of these spectra arise from $10.5 \mathrm{eV}$ alone. Likewise, the observation of metastable broadening of several low appearance energy ions suggests that these particular ions are not formed by absorption of an additional 355-nm photon. However, it is possible that several of the low abundance, low mass ions in these spectra originate from absorption of additional $355-\mathrm{nm}$ photons. Ideally the $355-\mathrm{nm}$ beam would be removed with a dichroic mirror, a filter [45], a prism, or off axis use of $\mathrm{MgF}_{2}$ lens [3].

\section{Acknowledgments}

This research was supported by grant no. CHE8614097 and CHE8918638 from the National Science Foundation. Assembly of the Xe/Ar cell was partially supported by the Biomedical Support Research Grant Program (2S07RR07013).

\section{References}

1. Ruhman, S.; Haas, Y.; Laukemper, J.; Preuss, M.; Stein, H.; Feldmann, D.; Welge, K. H. J. Phys. Chem. 1984, 88, 5162-5167.

2. Feldmann, D.; Laukemper, J.; Welge, K. H. J. Chem. Phys. 1983, 79, 278-282.

3. Schüle, U.; Pallix, J. B.; Becker, C, H. J. Am. Chem. Soc. 1988, 110, 2323-2324.

4. Schühle, U.; Pallix, J. B.; Decker, C. H. I. Vau. Sci. Technol. A 1988, 6, 936-940.

5. Pallix, J. B.; Schühle, U.; Becker, C. H.; Huestis, D. L. Anal. Chem. 1989, 61, 805-811.

6. Becker, C. H.; Jusinski, L. E.; Moro, L. Int. I. Mass Spectrom. Ion Processes 1990, 95, R1-R4.

7. Hilbig, R.; Wallenstein, R, Appl. Opt. 1982, 21, 913-917.

8. Mahon, R.; Mcllrath, T. J.; Myerscough, V. P.; Koopman, D. W. IEEE I. Quantum Electron. 1979, QE-15, 444-451.

9. Wallmeier, H.; Zacharias, H. Appl. Phys. B 1988, 45, 263-272.

10. Jamroz, W.; LaRocque, P. E.; Stoicheff, B. P. Opt. Lett. 1982, 7, 617-619.

11. Miyazaki, K; Sakai, H.; Sato, T. Opt. Lett. 1984, 9, 457-459.

12. Hilbig, R.; Hilber, G.; Lago, A.; Wolff, B.; Wallenstein, R. Comments At. Mol. Phys. 1986, 18, 157-180.

13. Kung, A. H.; Young, J. F.; Harris, S, E. Appl. Phys. Lett. 1973, 22, 301-302; 1976, 28, 294.

14. Bjorklund, G. C. IEEE I. Quantum Electron. 1975, QE-11, 287-296. 
15. Zych, L. J.; Young, J. F. IEEE I. Quantum Electron. 1978, QE-11, 147-149.

16. Field, F. H.; Hastings, S. H. Anal. Chem. 1956, 28, 1248-1255.

17. Lumpkin, H. E.; Aczel, T. Anal. Chem. 1964, 36, 181-184.

18. Johuisuin, B. H.; Aczel, T. Anul. Chem. 1967, 39, 682-685.

19. Aczel, T.; Hsu, C. S. Int. J. Mass Spectrom. Ion Pracesses 1989, 92, 1-7.

20. Bowen, R. D.; Maccoll, A. Org. Mass. Spectrom. 1983, 18, 576-581.

21. Bowen, R. D.; Maccoll, A. Org. Mass Spectrom. 1984, 19, $379-384$.

22. Bowen, R. D; Maccoll, A. J. Chem. Soc. Perkin Trans., 1985, 2, 1101-1103.

23. Bowen, R. D.; Maccoll, A. Org. Mass Spectrom. 1985, 20, $33 \mathrm{I}-335$.

24. Maccoll, A.: Mruzek, M. N. Org. Mass Spectrom. 1986, 21, 251-258.

25. Maccoll A. Org. Mass Spectrom. 1986, 21, 601-611.

26. Bowen, R. D.; Maccoll, A. I. Chem. Soc, Perkin Trans. 1987, 2, 1019-1025

27. Maccoll, A. Org. Mass Spectrom. 1988, 23, 381-387.

28. Brophy, J. J.; Maccoll, A. Org. Mass Spectrom. 1988, 23, 659-662.

29. Bowen, R. D.; Maccoll, A. Org. Mass Spectrom. 1989, 24, $113-122$.

30. Maccoll, A. Int. J. Mass Spectrom. Ion Processes 1988, 86. 227-234.
31. Brophy, J. J.; Shannon, J. S.; Maccoll, A.; Mruzek, M. N. Int. J. Mass Spectrom. Ion Processes 1989, 92, 9-13.

32. Arps, J. H.; Chen, C. H.; Mccann, M. P.; Datskou, I. Appl. Spectrosc. 1989, 43, 1211-1214.

33. Steiner, B.; Giese, C. F.; Inghram, M. G. I. Chem. Phys. 1961, 34, 189220.

34. Hoogerbrugge, R.; Bobeldijk, M.; Los, J. J. Phys. Chem. 1989, 93, 5444-5453.

35. Part, A. C.; Elder, F. A. I. Chem. Phys. 1968, 49, 2659-2664.

36. Refaey, K.; Chupka, W. A. J. Chem. Phys. 1968, 48, 5205-5219.

37. Berkowitz, J. I. Chem. Phys. 1978, 69, 3044-3054.

38. Hurzeler, H.; Inghram, M. G.; Morrison, J. D. J. Chem. Phys. 1958, 28, 76-82.

39. Murad, E.; Inghram, M. G. J. Chem. Phys. 1964, 40, $3263-3275$

40. Murand, E.; Inghram, M. G. J. Chem. Phys. 1964, 41, 404-409.

41. Villem, Ya. Ya.; Akopyan, M. E. Rus. J. Phys. Chem 1976, 50, 394-397.

42. Laporte, P.; Subtil, J. L.; Courbon, M.; Bon, M.; Vincent, L. J. Opl. Soc. Am, 1983, 73, 1062-1069.

43. Rhodes, G.; Opsal, R. B.; Meek, J. T.; Reilly, J. P. Anal. Chem. 1983, 55, 280-286.

44. Ruhl, E.; Price, S. D.; Leach, S. J. Phys. Chem. 1989, 93, 6312-6321.

45. Miller, J. C.; Compton, R. N.; Cooper, C. D. I. Chem. Phys. 1982, 76, 3967-3973. 